Document downloaded from:

http://hdl.handle.net/10251/49000

This paper must be cited as:

Paya Bernabeu, JJ.; Borrachero Rosado, MV.; Monzó Balbuena, JM.; Soriano Martinez, L.; Mitsuuchi Tashima, M. (2012). A new geopolymeric binder from hydrated-carbonated cement. Materials Letters. 74:223-225. doi:10.1016/j.matlet.2012.01.132.

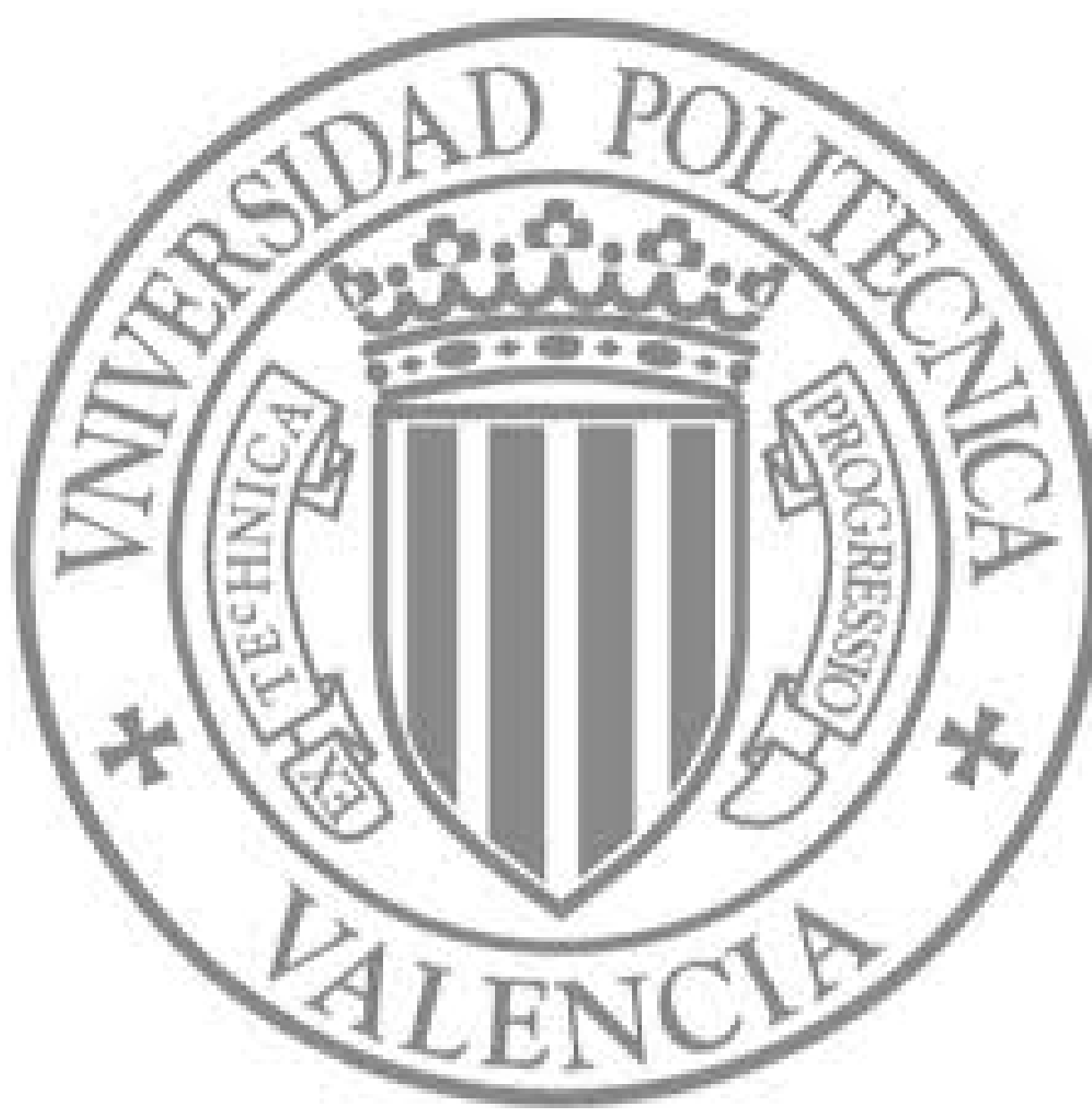

The final publication is available at

http://dx.doi.org/10.1016/j.matlet.2012.01.132

Copyright Elsevier 


\section{A new geopolymeric binder from hydrated-carbonated cement}

2 J. Payá*, M.V. Borrachero, J. Monzó, L. Soriano, M.M. Tashima.

3 jjpaya@cst.upv.es, vborrachero@cst.upv.es,jmmonzo@cst.upv.es, lousomar@upvnet.upv.es,

4 maumitta@ hotmail.com. Instituto de Ciencia y Tecnología del Hormigón. Universitat Politècnica de

5 València. Camino de Vera s/n, Edificio 4G, 46022 Valencia. Spain.

$6 \quad *$ Corresponding author: jjpaya@cst.upv.es, phone +34963877564.

$7 \quad$ Fax +34963877569

8 Abstract.

9 This paper evaluates the use of hydrated Portland cement as the raw material in the production of

10 geopolymers. The silicon and aluminium oxides needed for the geopolymerization process were produced

11 by the carbonation of hydrated Portland cement, which transforms CSH and CAH (Portland cement

12 hydrates) into silica and alumina gels. Hydrated-carbonated Portland cement was alkali activated with a

$13 \mathrm{NaOH} /$ waterglass solution. Pastes and mortars were prepared, and micro-structural and mechanical

14 properties were analyzed. It has been noted that geopolymers are mechanically stable and yield

15 compressive strength higher than $10 \mathrm{MPa}$ when mortars are cured at $65^{\circ} \mathrm{C}$ for three days. The results have

16 shown that there are interesting possibilities for re-using the cement-rich fraction of construction and

17 demolition waste. Alkaline activation of hydrated-carbonated Portland cement could be considered a low

$18 \quad \mathrm{CO}_{2}$-emission binder.

19 Keywords: low $\mathrm{CO}_{2}$-emission binder, carbonated cement, alkali activation, thermogravimetry,

20 construction and demolition waste 


\section{Introduction}

Different types of geopolymers [1] have been developed during the last decade and an alkali rich medium is needed in order to obtain the dissolution of silica and alumina from mineral addition in the geopolymerization process. The final product is usually a sodium alumino-silicate hydrate gel (NASH), a calcium alumino-silicate hydrate gel (CASH) or a sodium-calcium alumino-silicate hydrate gel (N,C)ASH )[2,3]. The nature and properties of geopolymers depend much on the mineral addition employed in the geopolymerization process. Mineral additions which have been commonly activated are metakaolin [4,5], ceramic waste [6] and mainly fly ashes and slags [3,7,8] as well the mixtures of them. In the geopolymerization process, a high concentration of alumino-silicate solution is obtained, because part of the solid (mineral addition) is leached. Usually, the alumina of the initial solid source is dissolved faster than silica [3] and sodium silicate is added to the alkaline solution to obtain good final properties in the geopolymerized solid. Thus, silica and alumina mixtures are required for the yielding of mechanically stable products in the alkaline medium [9].

Some advantages from the economic and the environmental point of view are noticeable when mineral additions are used in the preparation of geopolymers, compared to Portland cement: low cost, excellent durability, good mechanical and physical properties, low energy consumption, low greenhouse gas emissions, and finally the reutilization of solid waste. This last advantage is of a great importance for the residues that are being produced in large amounts. Probably, the most important of them is the construction and demolition waste (CDW). Part of CDW is recycled as aggregate and sand by using crushing and sieving methods. However, the other part of waste is difficult to recycle, e.g. aggregate washing silt (rich in clay, carbonates and quartz) and the rejected material in the recycling aggregate/sand (rich in hydrated cement and fine particles such as clay, gypsum, fine sand). Silt from washing of aggregates has been studied for its application in geopolymerization processes [10]. Compressive strength of 18.7 MPa was reported for geopolymers cured at room temperature after 7 days when 3.8 solid/liquid ratio mixture (9 $\mathrm{M}$ in $\mathrm{NaOH}$ and $4 \mathrm{M}$ in silicon for the activating solution used in paste dosage). Specimens were prepared by mixing solid powder with an alkaline solution and then these were pressed in a steel mould at $24 \mathrm{MPa}$. In the present paper, it is proposed the preparation of geopolymers from hydrated-carbonated Portland cement paste in order to evaluate the reuse of rejected fines from $\mathrm{CDW}$, which have an important percentage of hydrated Portland cement. Activation of fines from CDW had already been reported [10] in 
1 alkali activation. However, it is not clear how the reaction takes place. Probably, one of the processes involved is the activation of the hydrated-carbonated Portland cement fraction.

\section{Materials and methods}

Hydrated Portland cement was prepared by mixing 1000g of OPC with 5 litres of deionized water. The mix was shaken twice a day during one month in order to hydrate completely the OPC. The liquid phase was removed and the hydrated solid sample was left for 2 days in an open air atmosphere: the result was the hydrated cement. This material was extensively carbonated in a carbonation chamber in a $95 \% \mathrm{CO}_{2}$ atmosphere for 7 days: hydrated-carbonated cement sample was obtained, and it was ground in an alumina ball-mill for 30 minutes. Geopolymers were prepared by mixing $450 \mathrm{~g}$ of hydrated-carbonated cement, $1350 \mathrm{~g}$ of sand and also the alkaline solution, which was prepared as follows: $73.2 \mathrm{~g}$ of $\mathrm{NaOH}$, $337.5 \mathrm{~g}$ of waterglass $\left(\mathrm{SiO}_{2}=28 \%, \mathrm{Na}_{2} \mathrm{O}=8 \%, \mathrm{H}_{2} \mathrm{O}=64 \%\right)$ and $54.0 \mathrm{~g}$ of water. In this activating solution, the concentration of $\mathrm{Na}_{2} \mathrm{O}$ was $5 \mathrm{M}$ and the $\mathrm{SiO}_{2} / \mathrm{Na}_{2} \mathrm{O}$ molar ratio was 1.164 . Fresh mortar was put into a metallic mould to prepare $40 \times 40 \times 160 \mathrm{~mm}$ prismatic specimens and cured at $65^{\circ} \mathrm{C}$ for three days or cured for 3 days at room temperature. Pastes were also prepared by using the same proportion with no sand addition.

Granulometric characterization of hydrated-carbonated cement was determined by means of laser diffraction (Malvern Mastersizer 2000, in water suspension). FTIR spectra were recorded in a JASCO Mod-FT/IR-460 plus the use of Fourier Transformed Infrared Spectrometer (KBr Pellets, 4000-400 $\mathrm{cm}^{-1}$ ). Thermogravimetric characterization was carried out in a TGA 850 Mettler-Toledo thermobalance, by using $70 \mu \mathrm{L}$-alumina crucibles in an open air atmosphere in the $35-1000^{\circ} \mathrm{C}$ range at $20^{\circ} \mathrm{C} / \mathrm{min}$ heating rate. Ultimate compressive strength was determined according to standard UNE-EN-196-1, with the use of a universal testing machine. Three samples were tested in flexural mode and six samples were tested in compression. Mean values and standard deviation have been calculated. XRD pattern were collected in a Philips diffractometer PW1710 with $\mathrm{Cu}-\mathrm{K} \alpha$ radiation, under routine conditions of $40 \mathrm{Kv}$ and $20 \mathrm{~mA}$, from $2 \Theta=5-55^{\circ}$. Microscopic studies were carried out by SEM by using a JEOL-JSM-6300, equipped with energy dispersive X-ray (EDX) for microanalysis.

\section{Results and Discussion}

The hydrated cement sample contains mainly calcium hydroxide (portlandite), CSH and CAH as it can be seen in the thermogravimetric analysis (Figure 1). The hydration of anhydrous cement was completed 


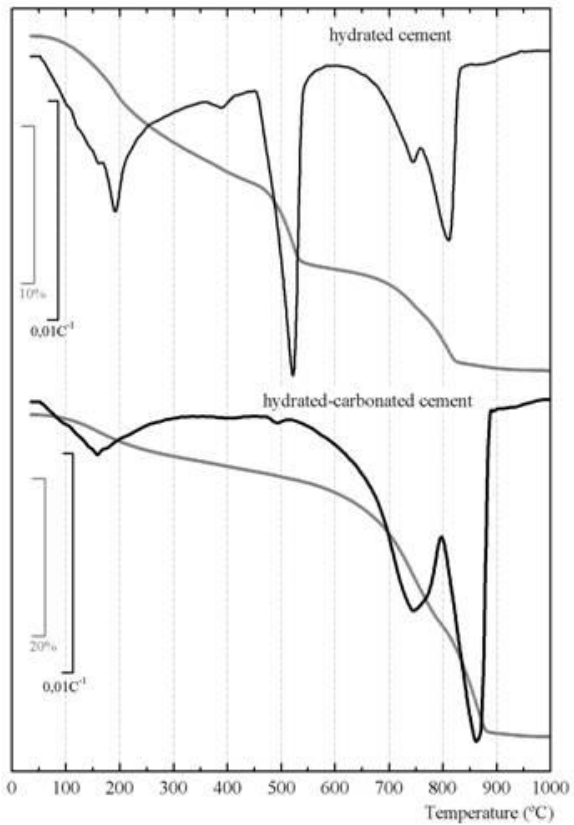

Figure 1. TG (grey lines) and DTG (black lines) curves: hydrated cement (up) and hydrated-carbonated cement (down). 
1 The paste prepared with hydrated-carbonated cement and water ( 0.6 water/solid ratio) did not harden after

23 days at room temperature and the thermogravimetric analysis showed the same pattern and composition

3 as the one observed previously in Figure 1. When the paste was prepared by using an alkaline solution

$4\left(\mathrm{NaOH} / \mathrm{Na}_{2} \mathrm{SiO}_{3}\right)$, it set in few minutes at $65^{\circ} \mathrm{C}$. Thermogravimetric curves (DTG curves) for pastes after

53 days at room temperature (paste A) and after 1 day at $65^{\circ} \mathrm{C}$ (paste B) are shown in Figure 2. It can be

6 noticed that the amount of water released at low temperature $\left(35-300^{\circ} \mathrm{C}\right)$ was higher than the one

7 measured for hydrated-carbonated cement. This behaviour suggests that silica and alumina gels in

8 hydrated-carbonated cement are chemically activated and new products are formed by geopolymerization.

9 Additionally, $\mathrm{CaCO}_{3}$ also evolved and the quantity was clearly reduced, thus shifting the decarbonation temperature (largest peak in DTG curve moves at lower temperatures, from $862^{\circ} \mathrm{C}$ for hydratedweight loss of TG for selected temperature ranges are shown.

Table 1. Loss of weight (\%) calculated from TG curves for selected temperature ranges

\begin{tabular}{ccc}
\hline Sample & \multicolumn{2}{c}{ Temperature range } \\
& $35-300^{\circ} \mathrm{C}$ & $300-1000^{\circ} \mathrm{C}$ \\
\hline Hydrated cement & 7.70 & 16.53 \\
Hydrated-carbonated cement & 4.68 & 31.47 \\
Paste A & 10.64 & 22.54 \\
Paste B & 10.69 & 22.66 \\
\hline
\end{tabular}

FTIR studies showed that there were significantly changes in the spectra when hydrated-carbonated cement and activated paste B are compared. Thus, carbonate anion asymmetric stretching shifted from 1434.8 to $1423.1 \mathrm{~cm}^{-1}$, and asymmetric vibration of $\mathrm{Si}-\mathrm{O}-\mathrm{Si}$ groups shifted from 1052.9 to $1010.5 \mathrm{~cm}^{-1}$. These data revealed that both silica gel and calcium carbonate in hydrated-carbonated cement are involved in the activation process. X-ray diffractogram for this sample showed a main mineral phase, calcite $\left(\mathrm{CaCO}_{3}\right.$, PDFcard 050586), and portlandite $\left(\mathrm{Ca}(\mathrm{OH})_{2}, \mathrm{PDF}\right.$ card 040733$)$ and vaterite $\left(\mathrm{CaCO}_{3}\right.$, PDFcard 240030) as minor crystalline phases. After alkaline activation, calcite was maintained as main phase, pirssonite $\left(\mathrm{Na}_{2} \mathrm{Ca}\left(\mathrm{CO}_{3}\right)_{2} \cdot 2 \mathrm{H}_{2} \mathrm{O}\right.$, PDFcard 220476) and mesolite $\left(\mathrm{Na}_{2} \mathrm{Ca}_{2}\left(\mathrm{Al}_{2} \mathrm{Si}_{3} \mathrm{O}_{10}\right)_{3} \cdot 8 \mathrm{H}_{2} \mathrm{O}\right.$, PDFcard 241064) were found as minor components, and there was a baseline deviation in the $2 \Theta=25-35^{\circ}$ range. 


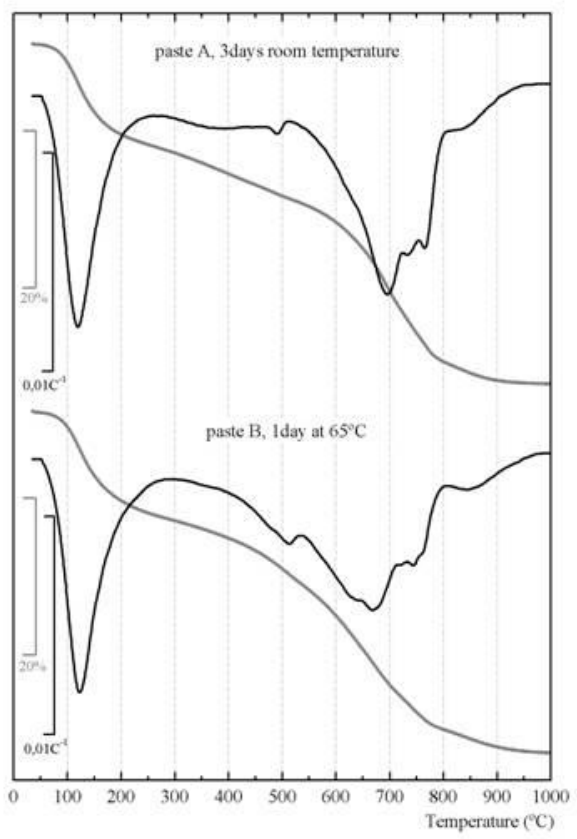

1

2 Figure 2. TG (grey lines) and DTG curves (black lines) for alkali activated pastes: paste A (up, 3 days of curing at room temperature) and paste $\mathrm{B}$ (down, 1 day of curing at $65^{\circ} \mathrm{C}$ ).

4

$5 \quad$ SEM studies on alkali activated pastes (fractured surface samples) showed the formation of an amorphous

6 matrix, rich in sodium, calcium and silicon. In Figure 3, a micrograph of the paste cured at $65^{\circ} \mathrm{C}$ for 1 day is shown, and a dense matrix of (N,C)ASH gel, probably mixed with calcium carbonate particles, was observed. Occasionally, small crystals rich in sodium and calcium, and attributed to the presence of sodium-calcium carbonates have been detected.
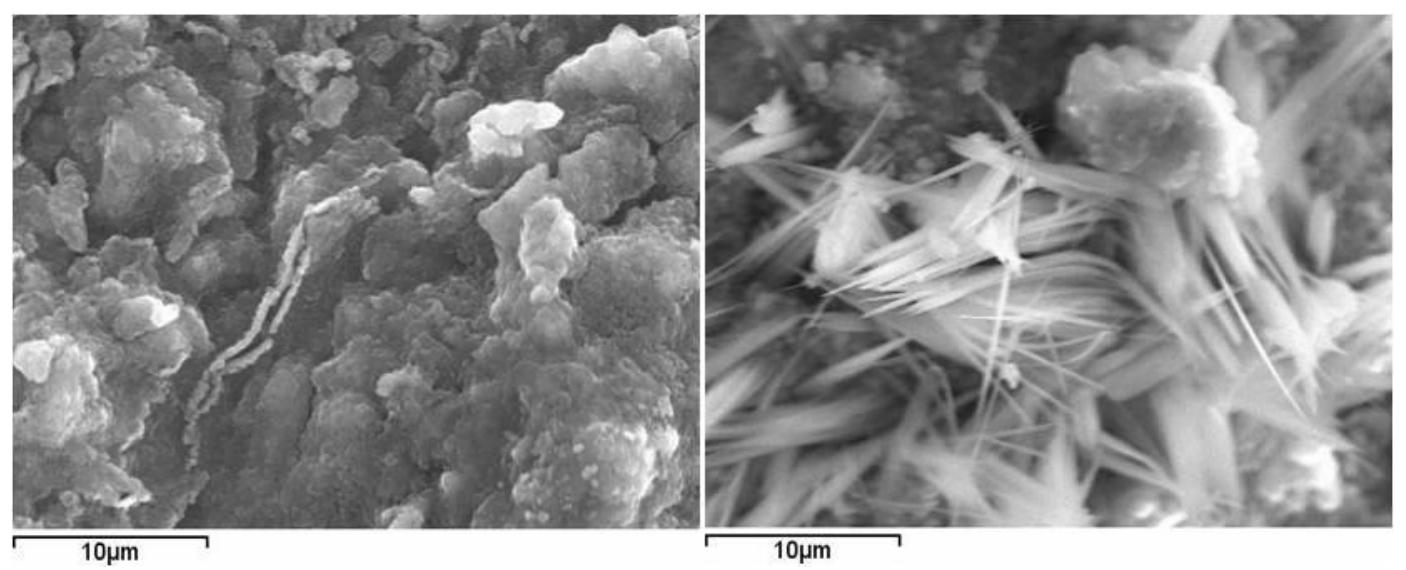

Figure 3. SEM micrographs of paste B (1 day of curing at $\left.65^{\circ} \mathrm{C}\right)$ : left, matrix; right, crystals. 
1 Finally, the stability of the geopolymers formed has been assessed by means of mechanical strength of mortars. Related to paste A, mortar cured at room temperature for 3 days was prepared, whose flexural strength was $1.34 \pm 0.12 \mathrm{MPa}$ and compressive strength was $6.31 \pm 0.24 \mathrm{MPa}$. These data revealed that the geopolymeric matrix formed had interesting mechanical properties, despite the low percentages of $\mathrm{SiO}_{2}$ $(14.61 \%)$ and $\mathrm{Al}_{2} \mathrm{O}_{3}(3.95 \%)$ in the hydrated-carbonated cement. Related to paste $\mathrm{B}$, mortar cured at $65^{\circ} \mathrm{C}$ for 3 days was also prepared: its flexural strength was $0.78 \pm 0.05 \mathrm{MPa}$ and compressive strength was 14.11 $\pm 0.42 \mathrm{MPa}$. These data revealed that the progress in the geopolymerization took place at higher temperatures, and an enhancement in the compressive strength has been reached.

\section{Conclusions}

Hydrated-carbonated cement can be activated by alkali-solutions and this causes geopolimerization of silica and alumina gels present in the carbonated material. This means that hydrated-carbonated cement could be considered a low $\mathrm{CO}_{2}$-emission binder. Geopolymers are mechanically stable, and yield compressive strength higher than $10 \mathrm{MPa}$ when mortars are cured at $65^{\circ} \mathrm{C}$. The results have shown that hydrated-carbonated cement can be alkali-activated, and that alkali activation could have a relevant potential use for the cement-rich fraction of $\mathrm{CDW}$, which has to be researched in the future.

\section{Acknowledgments}

Ministerio de Ciencia e Innovación (MICINN) of the Spanish Government (MAT-2011-19934 project) within FEDER funds.

\section{References}

[1] Davidovits J. Chemistry of Geopolymeric Systems Terminology. Proceedings of Geopolymer, International Conference, France; 1999.

[2] Xiao Y, Zhang Z, Zhu H, Chen Y. Thermochim Acta 2009;493:49-54.

[3] Shi C, Fernández-Jiménez A, Palomo A. Cem Con Res 2001; 41; 750-763.

[4] Muñiz-Villarreal MS, Manzano-Ramírez A, Sampieri-Bulbarela S, Ramón Gasca-Tirado J, ReyesAraiza JL, Rubio-Ávalos JC et al. Mater Lett 2011; 65; 995-998.

[5] Gasca-Tirado JR, Rubio-Ávalos JC, Muñiz-Villarreal MS, Manzano-Ramírez A, Reyes-Araiza JL, Sampieri-Bulbarela S et al. Mater Lett 2011; 65; 880-883. 
1 [6] Puertas F, Barba A, Gazulla MF, Gómez MP, Palacios M, Martínez-Ramírez S. Mater Construcc;

$2 \quad 2006 ; 56 ; 73-84$.

3 [7] Duxson P, Provis JL. J Am Ceram Soc; 2008; 91; 3864-3869.

4 [8] Pacheco-Torgal F, Castro-Gomes J, Jalali S. Constr Build Mater; 2008; 22; 1315-1322.

5 [9] S. Andini S, Cioffi R, Colangelo F, Grieco T, Montagnaro F, Santoro L. Waste Manage; 2008; 28;

$6 \quad 416-423$.

7 [10] Lampris C, Lupo R, Cheeseman CR. Waste Manage; 2009; 29; 368-373.

8 [11] Zornoza E, Garcés P, Monzó J, Borrachero MV, Payá J. Cem Con Comp 2009; 31; 134-138.

9 [12] Gartner EM, Macphee DE. Cem Con Res 2011; 41; 736-749.

10

11

12

13

14

15

16

17

18

19

20

21 
Figure 1. TG (grey lines) and DTG (black lines) curves for: hydrated cement (up) and hydratedcarbonated cement (down)

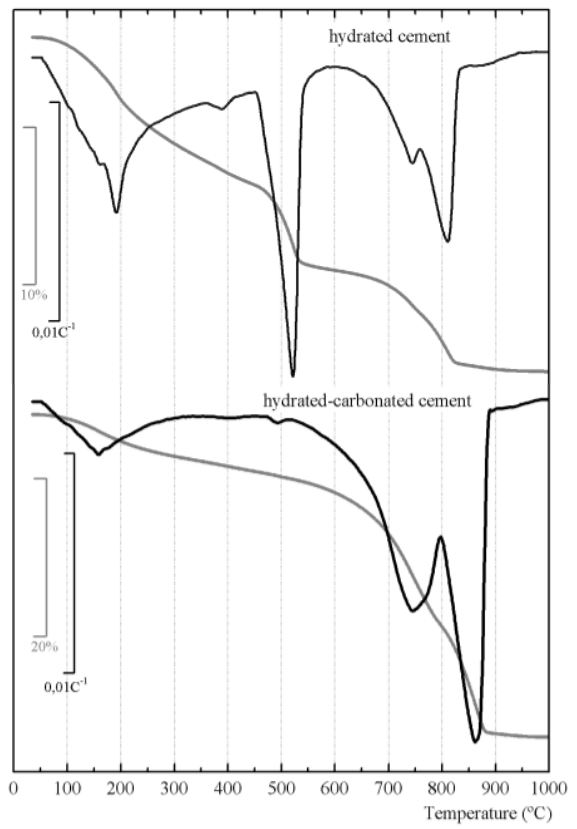

6

7 Figure 2. TG (grey lines) and DTG curves (black lines) for alkali activated pastes: paste A (up, 3 days of 8 curing at room temperature) and paste $\mathrm{B}$ (down, 1 day of curing at $65^{\circ} \mathrm{C}$ ) 


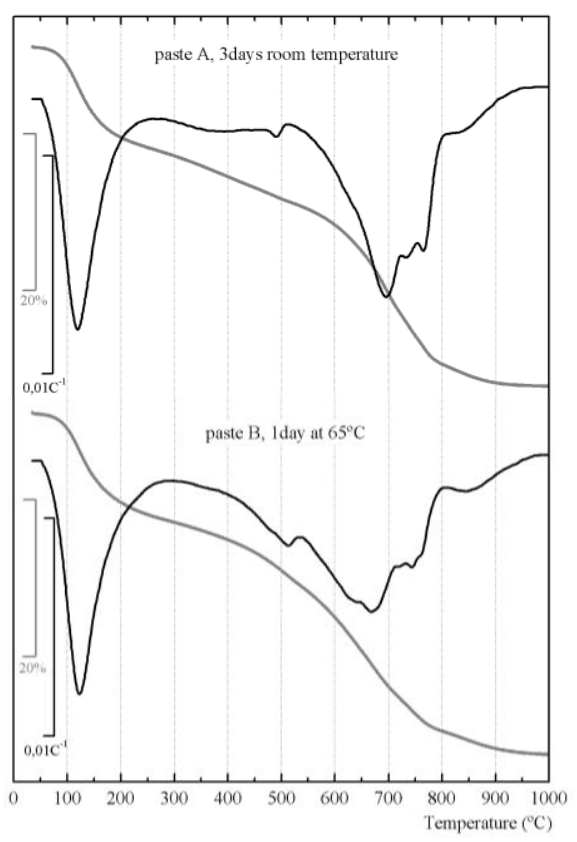

1

2

3

4 Figure 3. SEM micrographs of paste B $\left(1\right.$ day of curing at $\left.65^{\circ} \mathrm{C}\right)$ : left, matrix; right, crystals
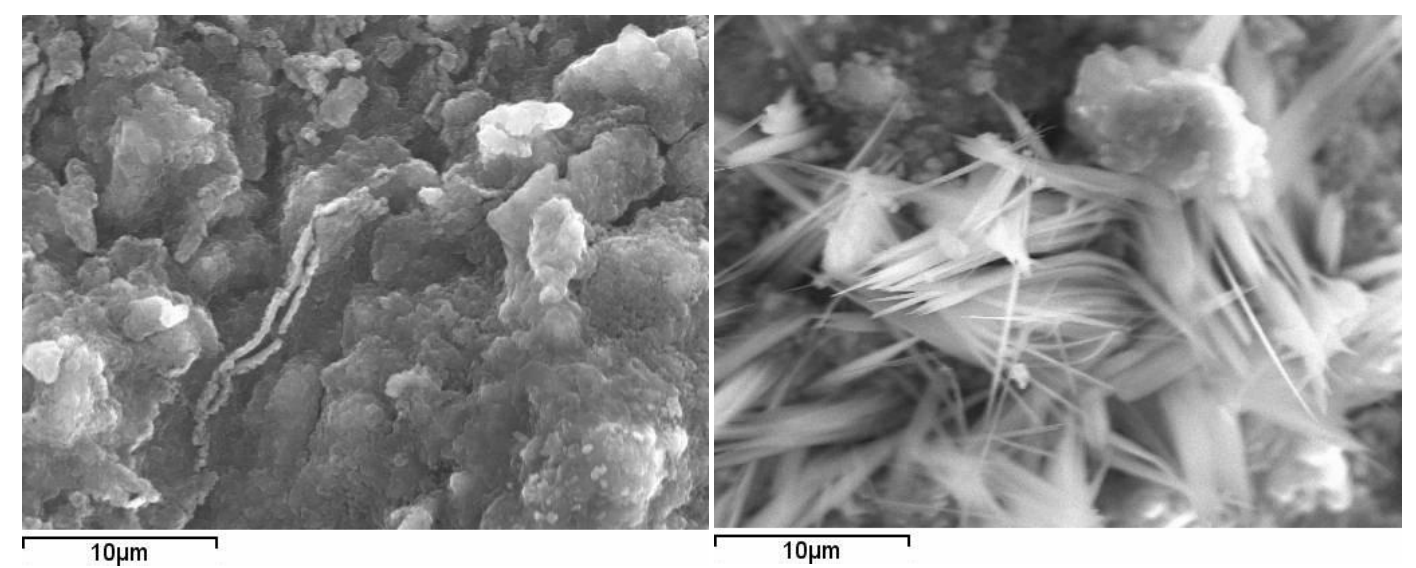

6

7 Table 1. Loss of weight (\%) calculated from TG curves for selected temperature ranges

\begin{tabular}{ccc}
\hline \multirow{2}{*}{ Sample } & \multicolumn{2}{c}{ Temperature range } \\
& $35-300^{\circ} \mathrm{C}$ & $300-1000^{\circ} \mathrm{C}$ \\
\hline Hydrated cement & 7.70 & 16.53 \\
Hydrated-carbonated cement & 4.68 & 31.47 \\
Paste A & 10.64 & 22.54 \\
Paste B & 10.69 & 22.66 \\
\hline
\end{tabular}

8 